\author{
Contato \\ Adriano Mafra \\ Rua João Bernardino da Rosa, 901 \\ 88137-010 - Palhoça - SC \\ adrianodeporto@gmail.com \\ Christiane Stallaert \\ University of Antwerp \\ Department of Translation and Interpreting \\ Schildersstraat, 41 \\ B-2000 - Antuérpia - Bélgica \\ christiane.stallaert@uantwerpen.be
}

\section{UM ORIENTALISTA}

ALEMÃO NO BRASIL

IMPERIAL. CHRISTIAN

FRIEDRICH SEYBOLD, O

TUTOR DE D. PEDRO I*

\author{
Adriano Mafra*
}

Núcleo de Estudo de Processos Criativos

Florianópolis - Santa Catarina - Brasil

\section{Christiane Stallaert*}

University of Antwerp

Antuérpia - Bélgica

\title{
Resumo
}

Este artigo visa discutir a relação entre o segundo imperador do Brasil, Pedro d'Alcântara, e seu último mestre de línguas semíticas e orientais, o alemão Christian Friedrich Seybold (1859-1921). Uma leitura preliminar dos diários do monarca nos chamou a atenção para a enorme quantidade de menções e referências àquele orientalista alemão, o que revela, de certa forma, a importância que o professor ocupava na vida de d. Pedro II. No entanto, ao passo que Seybold está presente em numerosas páginas dos diários, nos causa certa estranheza que tal fato tenha merecido pouca ou nenhuma consideração por parte dos biógrafos do imperador, já que o contato frequente entre eles durante cinco anos se resume a algumas poucas linhas e alusões esparsas. Partindo de uma releitura crítica do material disponível na historiografia brasileira sobre Seybold, pretendemos aportar novos dados para o estudo bio-bibliográfico daquele que foi uma figura atuante na vida intelectual de d. Pedro II, presente até os últimos dias de vida do soberano.

\section{Palavras-chave}

Brasil imperial - estudos orientais - Ch. F. Seybold.

* Este trabalho se insere no marco do projeto "D. Pedro II tradutor: análise do processo criativo" (CNPq), desenvolvido pelos pesquisadores do Núcleo de Estudo de Processos Criativos (Nuproc) sob a supervisão do prof. dr. Sergio Romanelli (UFSC).

** Doutor em Estudos da Tradução pela Universidade Federal de Santa Catarina e em Translation Science pela University of Antwerp - Bélgica. Membro do Núcleo de Estudo de Processos Criativos (UFSC). Professor colaborador da Faculdade Municipal de Palhoça e da Rede Municipal de Ensino em Bombinhas/SC.

${ }^{* * *}$ Doutora em Antropologia Social e Cultural e professora titular da Cátedra de Estudos Ibéricos e Comunicação Intercultural, Faculty of Arts, Department of Translation and Interpreting, University of Antwerp (Bélgica). Coordenadora do Grupo de Pesquisa Translation, Interpreting and Intercultural Studies. 


\author{
Contact \\ Adriano Mafra \\ Rua João Bernardino da Rosa, 901 \\ $88137-010$ - Palhoça - SC \\ adrianodeporto@gmail.com \\ Christiane Stallaert \\ University of Antwerp \\ Department of Translation and Interpreting \\ Schildersstraat, 41 \\ B-2000 - Antwerp - Belgium \\ christiane.stallaert@uantwerpen.be
}

\section{A GERMAN ORIENTALIST IN IMPERIAL BRAZIL. CHRISTIAN FRIEDRICH SEYBOLD, D. PEDRO II'S TUTOR}

\section{Adriano Mafra}

Núcleo de Estudo em Processos Criativos Florianópolis - Santa Catarina - Brazil

\section{Christiane Stallaert}

University of Antwerp

Antwerp - Belgium

\begin{abstract}
This article aims at discussing the relationship between the second emperor of Brazil, Pedro d'Alcântara, and his tutor of Semitic and oriental languages, the German orientalist Christian Friedrich Seybold (1859-1921). By reading the monarch's diaries we could find a huge amount of references to the German orientalist, which reveals, in a certain way, the importance of this tutor in d. Pedro II's life. However, whereas Seybold's presence is frequently observed in the emperor's diaries, strangely enough this close contact during five years was not taken into consideration by the emperor's biographers, being summarized in some lines and sparse allusions. From a critical rereading of the sources, we attempt to bring to light new data for the bio-bibliographic study of Seybold who contributed actively to d. Pedro II's intellectual life and who accompanied the emperor in exile until his last days of life.
\end{abstract}

\title{
Keywords
}

Imperial Brazil - oriental studies - Ch. F. Seybold. 


\section{Introdução}

D. Pedro II "morreu como estudante, pois na noite que precedeu à agonia, pediu ao doutor Seybold, seu professor de línguas mortas, que lhe lesse algumas páginas em sânscrito e notícias de jornais". Esta citação de Lídia Besouchet, ${ }^{1}$ bastante reveladora no que se refere à importância de Christian Friedrich Seybold (1859-1921) na vida de d. Pedro II, parece pertinente para marcar o início das nossas discussões. O ano era 1891, no modesto Hotel Bedford, em Paris. No leito de morte do monarca deposto estava, dentre familiares e os poucos súditos fiéis, Christian Seybold, seu último mestre de línguas semíticas e orientais. A ele coube a tarefa de escrever o epitáfio para a urna mortuária de Pedro II, e o fez evidenciando, entre outras características, a memória prodigiosa de seu aplicado pupilo. ${ }^{2}$

O contato entre Seybold e o imperador, porém, remonta ao ano de 1886. Nesta época, d. Pedro estava à procura de alguém que substituísse Carl Henning, seu anterior mestre de hebraico que decidira retornar para a Europa. Desde então, ele passou a assistir os estudos de Pedro II, dividindo-se entre a tarefa de ensinar línguas, sobretudo sânscrito, árabe, grego e hebraico, de discutir leituras e traduções, além de supervisionar os demais estudos filológicos do monarca. Os cinco anos subsequentes serão de muito trabalho em conjunto, intensificado no período de exílio da família imperial imposto pela queda da monarquia no Brasil. Os diários de d. Pedro II comprovam tal afirmação, como veremos detalhadamente mais adiante.

A proposta fundamenta-se a partir da análise crítica de algumas obras circunscritas no campo da historiografia brasileira que versam sobre a vida do segundo imperador do Brasil, Pedro d'Alcântara. Nossa atenção, porém, está centrada no último professor de línguas orientais do monarca, o alemão Christian Friedrich Seybold. Além das biografias, o corpus analisado está igualmente constituído por algumas referências inéditas no Brasil até então e por materiais de fonte primária, neste caso, o diário pessoal de d. Pedro II. Nosso objetivo, com base no cruzamento de informações e na apreciação crí-

\footnotetext{
1 BESOUCHET, Lídia. Pedro II e o século XIX. $2^{\mathrm{a}}$ edição revisada e ampliada. Rio de Janeiro: Nova Fronteira, 1993, p. 23.

2 CARVAlHO, José Murilo de. D. Pedro II: ser ou não ser. Coordenação de Elio Gaspari e Lilia M. Schwarcz. São Paulo: Companhia das Letras, 2007, p. 226. LYRA, Heitor. História de dom Pedro II: Declínio: 1880-1891. Belo Horizonte: Itatiaia, 1977b, p. 165.
} 
tica dos dados contidos nos materiais pesquisados, consiste em oferecer uma complementação do perfil biográfico e bibliográfico do orientalista alemão.

O presente artigo estrutura-se em três seções. Na primeira delas, apresentamos novos dados biográficos sobre Christian Friedrich Seybold, tendo o texto de Richard Hartmann ${ }^{3}$ como fonte principal de consulta. Escrito em alemão, o artigo de Hartmann apresenta certo grau de ineditismo no Brasil, já que não se configura como referência das obras que mencionam Seybold. Na segunda parte, recorremos a oito das principais biografias de d. Pedro II para verificar como a presença e a participação de Seybold na rotina de estudos do monarca estão evidenciadas em cada uma das obras. Finalmente, na terceira seção, nossas análises se concentram no diário pessoal do imperador Pedro II. A análise sistemática desse documento possibilitou verificar que a importância do professor alemão é muito maior do que as biografias de Pedro II costumam aludir.

Traçando um paralelo com as pesquisas realizadas no Nuproc ${ }^{4}$ sobre o perfil intelectual do imperador, buscamos aqui focar nesse personagem que viria a se tornar um expoente do orientalismo alemão no início do século XX, período posterior à época em que assessorou o monarca em seus estudos. De fato, o reconhecimento de Seybold como autoridade na área dos estudos orientais e o impacto de sua carreira acadêmica nas primeiras décadas do século XX podem ser conferidos pelo espaço destinado a sua produção em bibliotecas fora da Alemanha, como a Library of Congress, dos Estados Unidos, e a Bibliothèque St. Étienne de Jérusalem. Ambas mantêm as principais obras do orientalista alemão disponíveis em seu acervo. A importância da produção acadêmica de Seybold se reafirma também por outras vias, uma vez que o trabalho do professor continua se constituindo como base de consulta para

\footnotetext{
HARTMANN, Richard. Kleine Mitteilungen und Anzeigen. Christian Friedrich Seybold. Der Islam. Journal of the History and Culture of the Middle East, v. 12, n. 3-4. Berlim: De Gruyter, 1922, p. 202-206. Agradecemos ao pesquisador Denis Telles Rodrigues, membro do Nuproc, pela tradução do texto para o português.

4 Das pesquisas em andamento, citamos a tese de doutorado de Adriano Mafra intitulada $O$ processo criativo de d. Pedro II na tradução do "Hitopadeça" (2015). Nesta investigação, o autor analisa o processo de tradução para o português de uma obra escrita originalmente em sânscrito - o Hitopadeśa -, tarefa empreendida pelo monarca durante suas aulas com Seybold. Retomando a citação de Besouchet (1993) que abre este artigo, acrescentamos em tempo que se trata justamente do Hitopadeśa que d. Pedro II teria pedido que seu mestre orientalista lesse em seus últimos momentos de vida, visto que ele se dedicava à tradução da coletânea hindu naquele período.
} 
pesquisas publicadas nos últimos anos. ${ }^{5}$ Além disso, o autor contabiliza 16 artigos publicados na primeira edição da Encyclopaedia of Islam, ${ }^{6}$ uma das obras de referência para os estudiosos do mundo islâmico, editada entre os anos de 1913 e 1936 por M. Th. Houstsma, T. W. Arnold, R. Basset e R. Hartmann.

Vale a pena mencionar que a proposta que ora apresentamos deve ser tomada como uma contribuição e não como um estudo definitivo sobre a vida de Seybold. Pretende-se apenas dar visibilidade para este agente com vistas a possibilitar, a partir de novas investigações, uma renovação historiográfica sobre o real papel que o orientalista desempenhou na vida intelectual do monarca Pedro II durante o período de contato entre eles.

\section{O tutor do imperador}

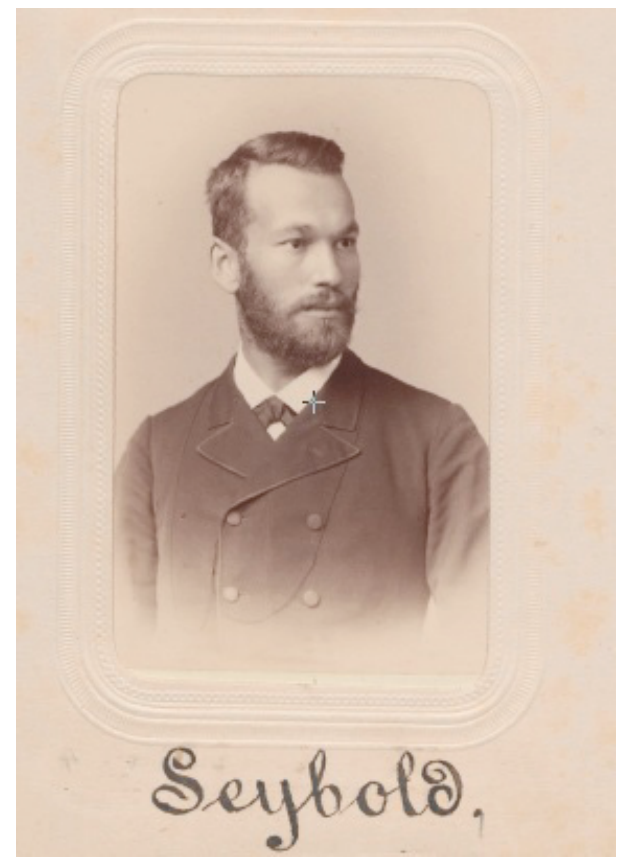

Figura 1: Christian Friedrich Seybold ${ }^{7}$

\footnotetext{
5 O leitor interessado encontrará no site WorldCat.org um mapeamento das principais bibliotecas que disponibilizam as obras de Christian Seybold. Além disso, salientamos que o site GoogleScholar.com reporta as principais obras contemporâneas que citam os trabalhos do orientalista alemão.

${ }^{6}$ HOUTSMA, Martijn Theodoor et al. First Encyclopaedia of Islam, 1913-1936. Leiden: Brill, 1936.

7 Imagem editada para fins deste artigo. Copyright: Tobias-Bild Universitätsbibliothek Tübingen. Disponível em: http://www.leo-bw.de/web/guest/detail/-/Detail/details/PERSON/wlbblb_per-
} 
rev. hist. (São Paulo), n. 173, p. 303-327, jul.-dez., 2015 http://dx.doi.org/10.11606/issn.2316-9141.rh.2015.106223
Adriano Mafra \& Christiane Stallaert

Um orientalista alemão no Brasil Imperial. Christian Friedrich Seybold, o tutor de d. Pedro II

Em "Kleine Mitteilungen und Anzeigen", publicado na $12^{\mathrm{a}}$ edição da revista Der Islam, Richard Hartmann ${ }^{8}$ oferece ao leitor alemão uma pequena biografia de Christian Friedrich Seybold, falecido no ano anterior à publicação. Contemporâneo e colega de Seybold na Universidade de Tübingen, Hartmann procura listar as principais obras daquele orientalista, evidenciando o seu particular método de trabalho e o dinamismo revelado nas diversas áreas em que atuou. Por ter sido produzido por alguém que conheceu e acompanhou a carreira profissional de Seybold, e publicado no ano seguinte à morte do professor alemão, o texto reporta dados consistentes que possibilitam reconstruir parte do perfil biográfico de Seybold. As linhas que seguem se baseiam, sobretudo, na produção de Hartmann. Como complemento, utilizamos ainda as publicações de Dibe (1922), Nallino (1923) e Van Ess (1980).

Christian Friedrich Seybold - ou Fritz Seybold, como preferem alguns biógrafos de d. Pedro II - nasceu em Waiblingen, no sul da Alemanha, em 6 de janeiro de 1859. Como muitos jovens de sua época, Seybold frequentou seminários evangélicos até ingressar na universidade. Em 1883, com apenas 24 anos, o jovem alemão recebia o título de doutor em Filosofia pela Universidade de Tübingen ${ }^{10}$ logo após licenciar-se em Teologia. Discípulo de Albert Socin, professor responsável pela revitalização dos estudos sobre o Oriente Médio naquela instituição, Seybold estudou também filologia com ênfase em línguas indo-europeias e semíticas. No mesmo período, Christian Seybold travou contato com o movimento orientalista ${ }^{11}$ da França e visitou pela primeira vez a região da Andaluzia, na Espanha. As primeiras impressões do lugar, segundo Hartmann, ${ }^{12}$ marcaram profundamente a vida daquele orientalista, uma vez que ele manteve um vívido interesse pela Espanha dos tem-

sonen/117475157/person. Acesso em: 21 jun. 2014.

8 HARTMANN, Richard, op. cit., 1922.

9 DIBE, Fück. Index Islamicus. Islam, n. 12, 1922, p. 202-206. NALLINO, Carlo Alfonso. Necrologie: Christian Friedrich Seybold. Revista Degli Studi Orientali, n. 9, 1921-1923, p. 234-5. ESS, Josef van. Christian Friedrich Seybold, professor für Orientalistik. 1859-1921. Lebensbilder aus Schwaben $u$. Franken, n. 14, Stuttgart, 1980, p. 416-432.

${ }^{10}$ NALLinO, Carlo Alfonso, op. cit., 1923, p. 234.

11 A propósito do trabalho dos orientalistas naquele período, Le Blanc (2012) cita Rosny (1891), que registrou o vínculo entre o orientalismo e a filosofia em uma publicação de 1891. Segundo o artigo, o orientalismo, baseado inicialmente na filologia comparada, viria a se tornar também um trabalho de cunho literário e filosófico. Aspiravam, à época, que os grandes orientalistas não fossem "mais meros intérpretes", mas sim "homens de pensamento". LE BLANC, Claudine. Une Antiquité nouvelle. In: CHEVREL, Yves; D'HULST, Lieven; LOMBEZ, Christine (ed.). Histoire des traductions en langue française. Lagrasse: Verdier, 2012, p. 189-254.

12 HARTMANN, Richard, op. cit., 1922, p. 202. 
pos árabes ao longo de sua carreira acadêmica. O ensaio Ibn al-Anbārī's Asrâr al-Arabiya, publicado em Leiden em 1886, teria motivado indiretamente a expedição. O resultado da viagem foi o trabalho de cunho filológico "Die arabische Sprache in den romanischen Ländern", publicado na edição de Gustav Gröber, intitulada Grundriß der romanischen Philologie (1888). De 1883 a 1886, o recém-doutor atuou como professor assistente em Heilbronn e Maulbronn, na Alemanha, e se ocupava nas horas vagas da edição das obras supracitadas.

$\mathrm{O}$ ano de 1886, no entanto, trouxe a oportunidade que Hartmann ${ }^{13}$ considera a responsável pela maior guinada na vida profissional de Seybold. A partir dessa data, ele pôde dedicar-se mais efetivamente à pesquisa e explorar um novo objeto de estudo que renderia publicações futuras, neste caso, a língua guarani. Naquele ano, o nome do orientalista alemão foi apontado tanto por especialistas de árabe quanto de sânscrito como candidato habilitado a auxiliar os estudos científicos de d. Pedro II, a quem ensinaria línguas semíticas e orientais, especialmente o árabe, o hebraico e o sânscrito. ${ }^{14}$ Em 1887, já no cargo de auxiliar de estudos literários do imperador, Seybold embarcaria para a Europa em companhia do monarca doente, que cruzava o Atlântico em busca de tratamento de saúde. Segundo Hartmann, ${ }^{15}$ as viagens que surgiram a partir do contato com o d. Pedro II, no Velho e no Novo Mundo, proporcionaram a Seybold não somente uma extensão de seu próprio conhecimento de mundo e das pessoas com quem passou a conviver. Trouxeram igualmente a possibilidade de familiarização com mais lugares de cultura árabe. Foi também a chance de travar contato com orientalistas da maioria dos países visitados pela comitiva imperial, em especial dos países de línguas românicas. As áreas de interesse de Seybold, as línguas e literaturas árabe, hebraica, siríaca e persa eram também foco de estudo do governante.

Durante sua estada no Brasil, Seybold se lançou nas pesquisas sobre línguas indígenas, o que culminou no trabalho de reedição de Brevis Linguae Guaraní Grammatica Hispanice ("Breve noticia de la lengua Guaraní") (1890), Arte de la lengua Guaraní (1892) e Lexicon Hispano-Guaranicum ("Vocabulario de la lengua Guaraní") (1893), obras de grande envergadura do missionário peruano Antonio Ruiz de Montoya, revisadas e ampliadas pelo padre Paulo Restivo. As três

\footnotetext{
${ }^{13}$ Ibidem.

${ }^{14}$ De acordo com Calmon (1975, p. 475), em novembro de 1886, foi publicada uma portaria que disponibiliza a Seybold um carro para seu serviço, o que nos permite afirmar que ele teria desembarcado no Brasil naquele ano. CALMON, Pedro. História de dom Pedro II. Rio de Janeiro: José Olympio, Brasília: INL, 1975.

${ }^{15}$ HARTMANN, Richard, op. cit., 1922, p. 203.
} 
edições, raríssimas, contavam com apenas umas poucas cópias quando receberam a atenção de Seybold. Foram produzidas sob os auspícios de d. Pedro II e dedicadas ao último monarca do Brasil. Para Hartmann, ${ }^{16}$ esses trabalhos revelam a versatilidade de Seybold, que encontrou no fascínio que tinha o imperador pelas línguas ameríndias a inspiração para se debruçar no seu estudo sistemático, trazendo a público as obras mais antigas já escritas sobre a língua guarani. Após a morte de d. Pedro II, em dezembro de 1891, Christian Seybold assumiu a cadeira de línguas semíticas da Universidade de Tübingen, permanecendo no quadro daquela instituição de ensino como professor por quase 20 anos. Iniciou a docência em 1893, mesmo ano em que trazia a público a obra "Relaciones sobre Pedro Teixeira", no evento Festgruss an Rudolf von Roth.

Segundo Werkmeister, ${ }^{17}$ Seybold foi o responsável por catalogar os manuscritos árabes da Biblioteca da Universidade que, desde 1521, já possuía um núcleo consolidado de Estudos Orientais vinculado à Faculdade de Teologia. Outro contemporâneo de Seybold, o italiano Carlo Alfonso Nallino, ${ }^{18}$ também assinala a versatilidade do orientalista alemão e comenta o seu rigoroso método de trabalho com os manuscritos de Tübingen, campanha que se converteu em muitas publicações importantes no âmbito dos estudos orientais. Para Nallino, ${ }^{19}$ Seybold se distinguiu sobretudo como editor de textos árabes, tendo publicado o Glossarium latino-arabicum (1900), cujo texto, extraído de um manuscrito encontrado em Leiden, apresenta informações preciosas sobre as origens das línguas românicas. Nos anos subsequentes, Seybold publicou Geschichte von Sul und Schumul: Unbekannte Erzählung aus Tausend und einer Nacht (1902), único manuscrito das Mil e uma noites que apresenta a história de amor dos primos Súl e Shumúl. De acordo com Kay, ${ }^{20}$ a peculiaridade desse conto está no seu forte sabor cristão, apresentando o narrador profundo conhecimento dos hábitos dos monges cristãos e eremitas da Síria. A obra foi dedicada à memória de d. Pedro II, cujo empenho em traduzir para o português os contos das Mil e uma noites diretamente do texto árabe foi devidamente salientado na edição. Segundo Jarouche, a dedicatória de

\footnotetext{
${ }^{16}$ HARTMANN, Richard, op. cit., 1922, p. 203.

${ }^{17}$ WERKMEISTER, Walter. The near and middle East collection of the University Library of Tübingen. Bulletin (British Society for Middle Eastern Studies), vol. 9, n. 1, 1982, p. 82-7.

${ }^{18}$ NALLINO, Carlo Alfonso, op. cit., 1923, p. 235.

${ }^{19}$ Ibidem.

${ }^{20} \mathrm{KAY}$, Charles de. The Arabian nights. The story of Sul and Schumul, oddly in a Christian setting. The New York Times. Nova York, 8 ago. 1903, p. BR5. (Seção The New York Times Saturday Review of Books and Art)
} 
Seybold demonstra "não só seu apreço sincero pela figura do então falecido imperador, como também a inesgotável curiosidade intelectual desse último". ${ }^{21}$ No mesmo ano, Seybold publicou também Die Drusenschrift: Kitāb Alnoqạt Waldawāir ("Das Buch der Punkte und Kreise") e um ensaio no Boletín de la Real Academia de la Historia, intitulado "La España musulmana. Notas geográficas". Nesta brevíssima nota, Seybold ${ }^{22}$ questiona alguns problemas de tradução do texto árabe do geógrafo Ibn Jaldún (1332-1406), o que traria implicações para se definir com precisão a topografia da região andaluza. Propunha ele na mesma época publicar o texto árabe na íntegra, acrescido de tradução e comentários. A cartografia islâmica medieval foi, portanto, outra área de interesse de Seybold. De acordo com Juan Piqueras Haba, ${ }^{23}$ a maior parte dos estudos publicados na Espanha sobre o território andaluz se baseava exclusivamente em textos manuscritos, desconsiderando os aspectos geográficos e sem fazer referências aos mapas já existentes devido à dificuldade em acessá-los. Era um trabalho realizado quase sempre por filólogos e historiadores. Eram poucos, naquela época, os privilegiados que recebiam autorização para pesquisar nos grandes arquivos europeus e o orientalista alemão poderia se considerar um dentre eles. Haba ${ }^{24}$ afirma ainda que Seybold teve em mãos cópia de um manuscrito raro produzido por Ibn Idrīsī (1099-1166), um misto de texto intercalado com cartografia da Espanha árabe, e tinha a intenção de publicar todo o manuscrito, mas faleceu antes de concluir seu intento.

Em 1904, Seybold editou a Historia patriarcharum Alexandrinorum, um dos trabalhos históricos de maior vulto da Igreja Ortodoxa Copta, compilado inicialmente pelo bispo Severus Ibn al Mukaffa em fins do século X. O segundo volume da edição foi publicado em 1910. Para Nallino, ${ }^{25}$ a grande erudição e o excelente método filológico de Seybold podem ser conferidos não só nos inúmeros artigos divulgados em revistas alemãs, mas também em um número igualmente extraordinário de edições publicadas em periódicos acadêmicos, especializados ou não em estudos orientais. A lista de grandes publicações do pesquisador alemão se encerra com Fleis-

\footnotetext{
${ }^{21}$ JAROUCHE, Mamede Mustafa. O desafio do tempo na tradução das Mil e uma noites. In: CICLO: DESAFIOS DA TRADUÇÃO LITERÁRIA. ABL, 2011, p. 73-88.

22 SEYBOLD, Christian Friedrich. La España musulmana. Notas geográficas. Boletín de la Real Academia de la Historia, tomo 40. Madri, 1902, p. 553-4.

${ }^{23}$ HABA, Juan Piqueras. Cartografía islâmica de Sharq Al-Andalus. Siglos X-XII. Al-Idrīsī y los precursores. Cua. de Geogr., n. 86. Valência, 2009, p. 137-164.

${ }^{24}$ HABA, Juan Piqueras, op. cit., 2009, p. 158.

${ }^{25}$ NALLINO, Carlo Alfonso, op. cit., 1923, p. 235.
} 
chers Briefe an Hassler aus den Jahren 1823 bis 1870 (1914), obra que, na opinião de Hartmann, ${ }^{26}$ deixa entrever a principal faceta da personalidade científica de Seybold, apresentando-o como um exímio filólogo. Aliás, as tarefas de cunho filológico ocuparam grande parcela da vida de Seybold. Sua força, diria Hartmann, ${ }^{27}$ era a penosa filologia da precisão, o que lhe possibilitou publicar diferentes modalidades de texto. A perícia de Seybold, entretanto, não se reduziu à esfera meramente linguística, uma vez que ele soube transitar entre a filologia, lexicografia, história da literatura e, especialmente, geografia e história da Espanha árabe. Por conta de tal versatilidade, seu nome está marcado na história do orientalismo germânico. ${ }^{28} \mathrm{~A}$ carreira de Seybold e seu ímpeto para o trabalho aos poucos foram sendo abreviados pelos primeiros sintomas da aterosclerose. ${ }^{29}$ Assim, Christian Friedrich Seybold, após longos sofrimentos causados pela doença, se afasta definitivamente do trabalho na Universidade de Tübingen, vindo a falecer pouco tempo depois, em 27 de janeiro de 1921, aos 62 anos de idade.

\section{Seybold nas biografias de d. Pedro II}

Nesta seção, apresentamos o resultado de uma pesquisa preliminar realizada a partir de um corpus representativo composto por oito biografias do monarca Pedro II. ${ }^{30}$ Priorizamos um recorte temporal que possibilitasse inserir obras mais próximas aos eventos da vida do imperador e também a inclusão de trabalhos mais recentes. O nosso interesse, nesse momento, consiste em verificar como os estudiosos da vida do monarca abordavam a participação de Seybold como seu tutor. A análise sistemática do material selecionado revelou o pouco espaço dedicado a Seybold nas biografias do imperador, como demonstraremos a seguir. Em contrapartida, a etapa sucessiva

\footnotetext{
${ }^{26}$ HARTMANN, Richard, op. cit., 1922, p. 204.

${ }^{27}$ Ibidem.

${ }^{28}$ Ibidem.

${ }^{29}$ NALLINO, Carlo Alfonso, op. cit., 1923, p. 235.

${ }^{30}$ As obras consultadas foram as seguintes: 1) D. Pedro II: ser ou não ser, de José Murilo de Carvalho (2007); (2) O imperador cidadão e a construção do Brasil, de Roderick J. Barman, lançado originalmente nos Estados Unidos (1999) e publicado no Brasil em 2010; (3) As barbas do imperador: D. Pedro II, um monarca nos trópicos, de autoria de Lilia Moritz Schwarcz (1998); (4) D. Pedro II e o século XIX, da pesquisadora Lídia Besouchet (1993); (5) História de dom Pedro II: Fastígio, 1870-1880; e (6) História de dom Pedro II: Declínio, 1880-1891, ambos da coletânea escrita por Heitor Lyra (1977); (7) História de dom Pedro II, tomo II: cultura e política, paz e guerra: 1853-1870, de Pedro Calmon (1975); e (8) Dom Pedro II: imperador do Brasil, produzida por Benjamin Mossé (1889).
} 
do trabalho, cujo foco é o diário pessoal de Pedro II, mostrará que Seybold ocupou lugar central nos últimos anos de vida do monarca. Além disso, vale a pena ressaltar que as fontes que reportamos anteriormente nos permitem assinalar alguns desencontros nas informações prestadas pelos historiadores.

O biógrafo que mais apresenta dados concernentes a Christian Seybold é Pedro Calmon. Segundo o autor, Seybold nasceu em "Weiblinden (sic), em 1859, concluíra os profundos estudos na Universidade de Tubinga, a que voltaria, como professor de línguas semitas". ${ }^{31}$ Calmon não revela quais seriam esses "profundos estudos" cursados por Seybold e mais adiante menciona duas publicações do orientalista, o ensaio Ibn al ambraris, Asrar al Arabiga (1886) e o Glossarium latino-arabicum, este último editado 24 anos após o primeiro livro citado. Na verdade, o hiato entre as duas obras foi de 14 anos, já que a primeira publicação do Glossarium aconteceu em 1900 e não em 1910, como sugere Calmon. O autor afirma ainda que o nascimento de Seybold ocorreu no primeiro dia do mês de janeiro de 1859, diferentemente de Hartmann, Dibe e Nallino ${ }^{32}$ que apontam para o dia 6 de janeiro daquele ano. Interessante observar que Calmon cita Nallino como referência de seu texto sobre Seybold, mas apresenta dados divergentes do autor italiano.

O biógrafo assinala também a participação de Manuel Antonio da Rocha Faria, mais conhecido pelo título nobiliárquico de visconde de Nioac, na seleção de Seybold como mestre de d. Pedro. Segundo Calmon, “o Visconde de Nioac incumbiu-se de substituí-lo [Henning] por outro jovem alemão, de quem ouvira falar nas águas de Baden-Baden, Christian Frederich Seybold". ${ }^{33}$ Naquele ano, cerca de quatro meses após Henning se desligar de sua função, Seybold viajava para o Brasil para preencher a vaga: "embarcou em Antuérpia, em setembro de 1886. Foi o último companheiro desses trabalhos que teve Pedro II".34 O candidato, na opinião de Calmon, atendia aos requisitos para exercer a função de tutor do monarca Pedro II: "sobravam-lhe modéstia, docilidade e honradez, reclamadas para o cargo"35 e Seybold o aceitou com o ordenado de 18 mil francos anuais. Além do mais, salienta Calmon, "a sua

\footnotetext{
${ }^{31}$ CALMON, Pedro, op. cit., 1975, p. 475.

32 HARTMANN, Richard, op. cit., 1922. DIBE, Fück, op. cit., 1922. NALLINO, Carlo Alfonso, op. cit., 1923, p. 204-5.

33 CALMON, Pedro, op. cit., 1975, p. 475.

${ }^{34}$ Ibidem

${ }^{35}$ Ibidem.
} 
bibliografia é digna do minucioso espírito germânico, de que foi [Seybold] um exemplo clássico". ${ }^{36}$

Em As barbas do imperador: D. Pedro II, um monarca nos trópicos (1998), Lilia Moritz Schwarcz faz um exaustivo estudo sobre como a monarquia tornouse um mito e encontrou, na figura altiva de d. Pedro II, a personificação para este ideal. Nas 623 páginas do livro em questão, encontramos apenas duas menções ao professor de línguas orientais do imperador:

[Dom Pedro] ajudou, de diferentes maneiras, o trabalho de cientistas como Martius, as pesquisas de Lund, de Gorceix, dos naturalistas Couty, Goeldi e Agassiz, dos geólogos O. Derby, Charles Frederick Hartt, do botânico Glaziou, do cartógrafo Seybold, além de vários outros naturalistas que estiveram no país. ${ }^{37}$

Na primeira delas, como podemos observar, Schwarcz comenta o mecenato do monarca Pedro II e seu incentivo aos homens da ciência. Na lista dos agraciados pela ajuda do governante, encontramos o nome de Seybold vinculado à cartografia. De fato, o alemão se dedicou a esta ciência, focando notadamente a região andaluza, mas não constituiu a cartografia a sua principal ocupação durante a sua estada no Brasil. Na segunda menção, já na metade final do livro, Schwarcz elenca o nome de Seybold entre os que escolheram partir no Alagoas rumo a Europa com a comitiva imperial, em novembro de 1889:

A saída de d. Pedro, todavia, não foi tão colorida, como retratada na pintura. Circundado por alguns exilados e outros autoexilados - Mota Maia, o conde Aljezur, os barões de Muritiba, os barões Loreto, a viscondessa da Fonseca Costa e o professor Seybold -, o imperador partiu no Alagoas, selando o fim da monarquia mas não do mito chamado d. Pedro. ${ }^{38}$

José Murilo de Carvalho também acredita que Seybold tenha se juntado ao grupo expatriado ainda no Brasil. Para ele, "na viagem de exílio, [d. Pedro II] levou junto o professor de sânscrito, Seybold, com quem tomou lições até os últimos dias". ${ }^{39}$ Seguindo o mesmo caminho, Lidia Besouchet ${ }^{40}$ acrescenta o nome do orientalista na relação da comitiva que seguiu o monarca banido rumo a Europa.

\footnotetext{
36 Ibidem.

37 SCHWARCZ, Lilia Moritz. As barbas do imperador: D. Pedro II, um monarca nos trópicos. São Paulo: Companhia das Letras, 1998, p. 131, grifos nossos.

${ }^{38}$ Ibidem, p. 463.

39 CARVALHO, José Murilo de, op. cit., 2007, p. 229.

40 BESOUCHET, Lídia, op. cit., 1993, p. 473.
} 
A informação apresentada pelos autores, no entanto, contradiz outros dois biógrafos de d. Pedro II: o já citado Pedro Calmon e Roderick J. Barman. Calmon ${ }^{41}$ afirma que Seybold já estava na Europa durante o golpe de 15 de novembro de 1889, mencionando documentos da mordomia imperial que fundamentam a sua assertiva. O orientalista acompanhava da Alemanha, segundo ele, a transformação política do Brasil após a proclamação da República e se juntou ao séquito imperial na França, continuando a rotina de estudos com o monarca exilado. No livro $O$ imperador cidadão (2010), o historiador norte-americano Roderick J. Barman corrobora Calmon ao afirmar que Christian Seybold estava de férias em seu país de origem durante a queda da monarquia no Brasil: "o Dr. Christian Friedrich Seybold, seu professor de línguas que estivera em férias na Alemanha durante os acontecimentos de novembro de 1889, estava entre os que o recepcionaram na estação". ${ }^{2}$ Barman não traz informações biográficas sobre o professor alemão, mas o apresenta como um "linguista de incontestável habilidade". ${ }^{43}$ Por isso, ao analisar alguns dos trabalhos realizados por d. Pedro durante o exílio, o autor arrisca dizer que é impossível de se "determinar quanto da tradução em si deve ser atribuída a Seybold e quanto a D. Pedro". ${ }^{44}$

Em História de d. Pedro II: Fastígio (1870-1880), Heitor Lyra apresenta o jovem "C. Fritz Seybold" como um "homem grandemente erudito, professor de línguas orientais" ${ }^{\prime \prime 5}$ do imperador d. Pedro II. No volume subsequente da mesma coleção, dedicado à última década de vida do monarca (Declínio, 1880-1891), Lyra pontua que Seybold, no papel de substituto imediato de "Carlos Hering", 46 acompanhara o monarca em sua terceira viagem ao exterior (1877) ou, como denomina Calmon, na "viagem de doente". ${ }^{47}$ Lyra volta a citar Seybold outras duas vezes como o autor do epitáfio da urna mortuária do imperador, transcrevendo a mensagem em latim elaborada por ele que valoriza, sobretudo, a

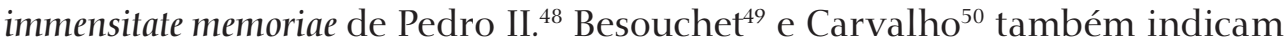

\footnotetext{
${ }^{41}$ CALMON, Pedro, op. cit., 1975, p. 475.

${ }^{42}$ BARMAN, Roderick J. $O$ imperador cidadão e a construção do Brasil. São Paulo: Unesp, 2010, p. 529.

43 Ibidem, p. 551.

${ }^{44}$ Ibidem

${ }^{45}$ LYRA, Heitor. História de dom Pedro II: Fastígio: 1870-1880. Belo Horizonte: Itatiaia, 1977a, p. 103.

${ }^{46}$ LYRA, Heitor. História de dom Pedro II: Declínio: 1880-1891. Belo Horizonte: Itatiaia, 1977b, p. 56.

${ }^{47}$ CALMON, Pedro, op. cit., 1975, p. 475.

${ }^{48}$ LYRA, Heitor, op. cit., 1977b, p. 165-6.

49 BESOUCHET, Lídia, op. cit., 1993, p. 623.

50 CARVALHO, José Murilo de, op. cit., 2007, p. 240.
} 
Seybold em meio aos que acompanharam os momentos finais de vida e que prestaram as últimas homenagens durante as exéquias do ex-imperador. Uma das primeiras biografias de d. Pedro II é a obra Dom Pedro II: imperador do Brasil, do rabino de Avignon Benjamin Mossé. ${ }^{51}$ Editada originalmente na França em 1889, a obra tem importância pelo pioneirismo do autor em se dedicar ao registro da vida do monarca ainda em vida do biografado. Em uma passagem de sua obra, Mossé enumera os professores que atuaram na infância e juventude do imperador, comentando a seguir que d. Pedro II tivera muitos outros mestres e que tinha notícias de que o monarca continuava estudando no período de preparação do livro:

Eis os nomes de alguns dos professores do jovem imperador: A. Boulanger - leitura; Boiré - lingua francêsa; Nathanael Lucas - lingua inglêsa; Dr. Roque Schuch - lingua allemã; Felix Emilio Taunay - geographia e historia; bispo de Chrysopolis - religião, lingua latina, mathematicas; marquês de Sapucahy - literatura; Alexandre Vaudelli sciencias naturaes; Simplicio Rodrigues de Sá (discipulo de J. B. Debret) - pintura. D. Pedro II teve muitos outros professores e, ainda hoje, um sábio, continua estudante. Assim o vimos em Cannes - e em Aix-les-Bains. ${ }^{52}$

Seybold já atuava como tutor de d. Pedro II quando a obra foi publicada, mas seu nome não aparece mencionado na edição, nem mesmo o nome dos mestres orientalistas que o antecederam. O fato de não ter sido citado na obra de Mossé pode ser justificado pelo período de preparação do volume. À época anterior a 1889, como veremos na etapa subsequente, Seybold iniciava seus trabalhos com o monarca. É um período em que o soberano ainda controlava as rédeas do governo e não dispunha de tanto tempo quanto gostaria para seguir com seus estudos. Como nos lembra Barman, "seu papel como imperador era tal que, para uma pessoa consciente de seus deveres e das necessidades de seu país, exigia longas horas de trabalho".53 É a partir dessa data, 1889, que o nome "Seybold" passará a ser uma constante no diário de d. Pedro II. Obviamente que as obras mais atuais buscam referências em trabalhos publicados anteriormente. Assim, a obra do rabino serviu de fonte

\footnotetext{
${ }^{51}$ MOSSÉ, Benjamin. Dom Pedro II imperador do Brasil. São Paulo: Edições Cultura Brasileira S/A, 1889. Calmon (1975, p. 476) defende que a autoria da obra é, na verdade, do barão do Rio Branco. Schwarcz (1998, p. 599), menos incisiva, comenta a mesma questão sobre o verdadeiro autor da obra: "ao que parece, apesar de formalmente a autoria ser de Mossé, a biografia teria sido escrita pelo próprio barão do Rio Branco".

${ }^{52}$ MOSSÉ, Benjamin, op. cit., 1889, p. 36.

53 BARMAN, Roderick J., op. cit., 2010, p. 281.
} 
de pesquisa para as principais biografias que surgiram em seguida, inclusive nas obras que remetemos neste artigo. Talvez se Mossé tivesse dedicado algumas linhas ao orientalista alemão, já que ambos eram contemporâneos e ele poderia ter acesso direto ao professor, a informação possivelmente teria sido retomada em trabalhos posteriores.

\section{Seybold nos diários do imperador}

Em 1887, d. Pedro II recebia dos médicos a recomendação de uma viagem à Europa para tratamento de saúde. Se a primeira viagem tinha motivações no desejo de conhecer o mundo e a segunda encontrava na doença da imperatriz justificativa plausível, a terceira delas, comentavam, seria para encobrir a fraqueza e debilidade física de d. Pedro II. ${ }^{54}$ Naquela ocasião, além de ser acometido por febres incessantes, o seu corpo já sentia o peso da idade e a memória de curto prazo, de acordo com Barman, ${ }^{55}$ também estava prejudicada. O embarque ocorreu em 30 de junho e a viagem duraria alguns meses. Em 2 de julho, d. Pedro II faria a nominata dos companheiros de bordo em seu diário pessoal: "Vem a bordo Nioac e filho Alberto; Carapebus, mulher e a Helena; Drs. Mota Maia e família e Sabóia com a filha solteira". ${ }^{56}$ Na sequência, anuncia o número de pessoas que viajavam no Gironde. Um dos passageiros permaneceria incógnito não fosse a menção que o destacava em meio aquela multidão. Era Seybold, seu professor de línguas orientais, pela primeira vez mencionado no diário de d. Pedro II: “Comecei um soneto de despedida hoje acabado e fiz charadas. Há 500 passageiros entre os quais o Seibold com quem continuarei meu estudo de sânscrito, árabe e grego". ${ }^{57} \mathrm{~A}$ partir dessa data, encontraremos o nome de Seybold em outras 778 citações, sendo a última em 28 de novembro de 1891. A bordo do Gironde e em território europeu, o nome do professor esteve vinculado, principalmente, à atividade de tradução. ${ }^{58}$ Com ele, d. Pedro conferia a tradução dos Lusíadas para o

${ }^{54}$ SCHWARCZ, Lilia Moritz, op. cit., 1998, p. 431.

55 BARMAN, Roderick J., op. cit., 2010, p. 471.

${ }^{56}$ ALCÂNTARA, Pedro de. Diário do imperador d. Pedro II. Organização: Begonha Bediaga. Petrópolis: Museu Imperial, 1999, p. 636.

${ }^{57}$ Ibidem. D. Pedro registra apenas uma vez o nome do orientalista com a grafia correta (Seybold). Em todas as outras, refere-se a "Seibold".

${ }^{58}$ Segundo Stallaert e Romanelli (2015), a tradução, juntamente com a escrita e a educação, constituía um dos pilares da incansável política cultural do imperador que objetivava a construção de uma identidade nacional letrada para o país. Muitas de suas produções, algumas jamais publicadas, estão sendo pesquisadas pelos membros do Nuproc (www.nuproc.cce.ufsc.br). Parte 
alemão e a comparava com o original, além de traduzir sânscrito, árabe, grego e hebraico. Do árabe, esteve envolto com as Mil e uma noites, do grego, traduzia a Odisseia e, do hebraico, se ocupou de um cumprimento de um judeu de Paris. As lições com o Seybold, nos meses de julho a setembro de 1887, não aconteciam em um horário pré-determinado, podendo ocorrer no final da manhã e, sobretudo, no período vespertino, conforme notas do diário:

8 de julho de 1887: 3 h 1/2 Traduzi desde 2 1/2 sânscrito com o Seibold. Jantei bem..$^{59}$ 13 de julho: 5 1/2. Acabei de jantar. Antes do jantar traduzi a Odisseia com o Seibold comparando-a à tradução alemã. ${ }^{60}$

26 de agosto: 10 1/4. Acabo de almoçar. Hei de dar lição com o Seibold. ${ }^{61}$

15 de setembro: 5 h 5' Lição do Seibold de alemão como da vez passada. ${ }^{62}$

Em algumas passagens, o imperador é mais direto e não especifica o tratado de seus estudos, simplesmente faz registros de forma mais genérica e abrangente, como em 15 de agosto: "Vou estudar com o Seibold";63 ou em 17 de setembro: "13/4. Lição com o Seibold". ${ }^{64}$

Em 30 de setembro, Seybold despede-se do monarca e segue para $\mathrm{Pa}-$ ris. Os estudos iniciados na companhia de seu professor são suspensos nos meses subsequentes, tendo o imperador se dedicado a atividades de cunho cultural e de interesse particular, como a visita a museus, igrejas, óperas etc. e aos compromissos de chefe de estado. Voltaria a incluir a tradução em sua rotina diária em 20 de novembro, vertendo do francês, idioma que dominava desde muito cedo, um poema de Gustave Nadaud. Não abriu mão, porém, das leituras na ausência de seu tutor. Lia diariamente os jornais de alguns países, artigos de revista, obras literárias e as cartas de seus interlocutores. Com o retorno de Seybold, em janeiro de 1888, d. Pedro II resgata o estudo de línguas orientais. O monarca afirma traduzir do sânscrito o livro Hitopadeśa, comemorando não ter esquecido o que aprendeu, apesar da interrupção daquele estudo nos meses anteriores. ${ }^{65}$ Do hebraico, passa a verter Nehemias,

\footnotetext{
das pesquisas em andamento foi publicada em SOARES, Noêmia Guimarães; SOUZA, Rosane de; ROMANELLI, Sergio (org.). Dom Pedro II: um tradutor imperial. $1^{\text {a }}$ edição. Tubarão: Copiart, 2013.

59 ALCÂNTARA, Pedro de, op. cit., 1999, p. 642, grifos nossos.

${ }^{60}$ Ibidem, p. 648, grifos nossos.

${ }^{61}$ Ibidem, p. 664, grifos nossos.

${ }^{62}$ Ibidem, p. 669, grifos nossos.

${ }^{63}$ Ibidem, p. 661, grifos nossos.

${ }^{64}$ Ibidem, p. 670, grifos nossos.

65 Ibidem, p. 728.
} 
segundo ele com facilidade, e continua a comparação da edição alemã dos Lusíadas com o original português, iniciada na viagem do Brasil a Lisboa. Além disso, o grego e o árabe continuam a fazer parte da rotina de estudos com a tradução da Odisseia e das Mil e uma noites. Os estudos, nesse ano, se concentravam no período da tarde e no turno da noite, às vezes constituindo o encontro com Seybold uma das atividades finais do dia do imperador, encerrado com a leitura de algum livro já na cama. A última menção ao Seybold nas páginas do diário de 1888 acontece em 25 de abril e o diário se encerra em 4 de maio do corrente ano.

O ano de 1889 marca a queda da monarquia no Brasil. Os registros no diário do monarca, cessados no ano anterior, serão retomados no fatídico mês de novembro. Em 29 de dezembro, já destituído do trono e agora viúvo, Pedro II comenta que passará a viver para o estudo que, infelizmente, na sua concepção, quase não trará proveito senão para ele próprio e para seus netos. ${ }^{66}$ No mesmo dia, reclama da falta que Seybold faz para os seus trabalhos linguísticos, validando a tese de Calmon (1975) e Barman (2010) de que o seu professor não estaria no Brasil durante o golpe republicano. Com o passar do tempo, a permanência de Seybold junto ao monarca será quase que integral. A presença do orientalista nas páginas do diário aumentará gradativamente e será uma constante à medida que os compromissos de governante são extintos. Assim, o professor ganhará importância maior nos dois anos finais da vida de Pedro II, que destinava cada vez mais tempo aos estudos, especialmente após a morte da imperatriz. A dedicação ao estudo foi a válvula de escape encontrada pelo monarca para seguir adiante e a presença de Seybold foi imprescindível para que ele levasse a cabo os compromissos diários que planejara para o exílio. A tabela abaixo resume em números a participação efetiva do orientalista nos estudos de d. Pedro II. Note-se que os anos finais concentram o maior número de menções ao orientalista alemão:

\section{Quadro 1:}

Quantidade de citações ao orientalista Seybold no diário do monarca Pedro II

\begin{tabular}{|c|c|c|c|c|c|}
\hline $\begin{array}{c}30.06 \text { a } 31.12 \\
\mathbf{1 8 8 7}\end{array}$ & $\begin{array}{c}01.01 \text { a } 04.05 \\
\mathbf{1 8 8 8}\end{array}$ & $\begin{array}{c}06.11 \text { a } 31.12 \\
\mathbf{1 8 8 9}\end{array}$ & $\begin{array}{c}01.01 \text { a } 31.12 \\
\mathbf{1 8 9 0}\end{array}$ & $\begin{array}{c}01.01 \text { a } 01.12 \\
\mathbf{1 8 9 1}\end{array}$ & TOTAL \\
\hline 18 & 40 & 2 & 276 & 443 & $\mathbf{7 7 9}$ \\
\hline
\end{tabular}

\footnotetext{
${ }^{66}$ Ibidem, p. 827.
} 
Em 16 de janeiro de 1890, d. Pedro e Christian Seybold voltariam a se encontrar em Cannes. Ainda na estação de trem, d. Pedro recebeu os livros que o professor usaria nas lições futuras e acertaram um encontro diário sempre às 3 horas, ${ }^{67}$ mas as aulas não seguiram esse cronograma, ocorrendo em horários bastante alternados. Além das obras que vinha traduzindo, d. Pedro inicia a tradução do livro de Isaías e incorpora a língua guarani aos estudos. Pedro II continua os registros como fazia outrora, às vezes detalhando o assunto de suas classes; em outros momentos, anotando simplesmente de maneira geral que estudaria com o Seybold. Em outros ainda, o nome do orientalista alemão, sozinho, passa a abarcar uma série de atividades. No decurso daquele ano, ao evocar o nome Seybold, está subentendido aí que é chegada a hora de traduzir, ler, comparar, ouvir leituras, enfim, hora do estudo propriamente dito:

13 de junho de 1890: 2 h Vou para o Seibold. 8 h 20' na sala de bilhar. ${ }^{68}$

11 de julho: 5 h 50' Seibold. Árabe e Camões. Depois saí a passeio. ${ }^{69}$

28 de agosto: 1 h $1 / 2$ Seibold..$^{70}$

04 de setembro: Daqui a pouco tenho Seibold. ${ }^{71}$

12 de setembro: $1 \mathrm{~h} 40^{\prime}$ Volto a Sand e agora Seibold. No concerto. ${ }^{72}$

17 de novembro: Estou bem disposto à espera do Seibold. ${ }^{73}$

27 de novembro: 5 h Boulevard Jeanne d'Arc. Desci em parte a pé. Seibold. ${ }^{74}$

Esse tipo de registro passa a ser cada vez mais recorrente, se estendendo inclusive para o ano de 1891:

11 de janeiro de 1891: (...) como não tenho hoje Seibold vou ao Didon. ${ }^{75}$

18 de fevereiro: Agora Seibold. ${ }^{76}$

8 de março: Se Seibold quiser vou aproveitar meia hora. ${ }^{77}$

5 de julho: Vou descansar meia hora até Seibold. ${ }^{78}$

\footnotetext{
${ }^{67}$ Ibidem, p. 842.

${ }^{68}$ Ibidem, p. 940, grifos nossos.

${ }^{69}$ Ibidem, p. 960, grifos nossos.

${ }^{70}$ Ibidem, p. 990, grifos nossos.

${ }^{71}$ Ibidem, p. 994, grifos nossos.

${ }^{72}$ Ibidem, p. 999, grifos nossos.

73 Ibidem, p. 1.037, grifos nossos.

${ }^{74}$ Ibidem, p. 1.044, grifos nossos.

${ }^{75}$ Ibidem, p. 1.069, grifos nossos.

${ }^{76}$ Ibidem, p. 1.084, grifos nossos.

${ }^{77}$ Ibidem, p. 1.104, grifos nossos.

${ }^{78}$ Ibidem, p. 1.198, grifos nossos.
} 
31 de agosto: 4 3/4 Seibold. 6h Persa, árabe e Camões. ${ }^{79}$

10 de setembro: $2 \mathrm{~h} 25^{\prime}$ Seibold. ${ }^{80}$

14 de novembro: $8 \mathrm{~h} 55^{\prime}$ Seibold. Tenho estado com o Aljezur. ${ }^{81}$

Os diários de 1890 e 1891 revelam uma espécie de dependência da presença de Seybold na vida cotidiana do antigo imperador. Além de auxiliar nos exercícios linguísticos durante o dia, Seybold, desde dezembro de 1890, passa a realizar leituras em voz alta para d. Pedro II na hora de dormir. Foram várias as vezes em que o monarca se mostrou incomodado com a ausência de seu tutor, como em 14 de dezembro de 1890: "Não sei se Seibold virá. Não conto com ele aos domingos". ${ }^{82}$ O fato de o professor não comparecer no horário combinado causava certa insegurança em d. Pedro II, pois teria de mudar seus planos de última hora. Em abril de 1891, ele revela textualmente o seu desconforto: "Seibold tarda e não sei o que faço". ${ }^{33}$ Do mesmo modo, escrevia ele em novembro: "procurei Seibold para estudar com ele. Tinha saído". ${ }^{84}$ Ainda no penúltimo mês do ano, Seybold se ausenta pouco mais de uma hora após o encontro diário e o monarca já se pergunta se o tutor retornará para a leitura em voz alta: "quando voltará o Seibold?". ${ }^{85}$

Seybold também parece demonstrar cansaço e impaciência com as muitas horas que despende para atender seu aluno. Tal qual uma criança que requer a leitura para poder adormecer, $d$. Pedro exige a presença de seu mestre orientalista já tarde da noite. A sonolência que o acometia frequentemente era a chance que Seybold encontrava para pôr fim ao encontro. Quando d. Pedro II tornava a acordar, o professor já se tinha ido: "a leitura fez-me sono e passei pelo sono. E o Seibold desapareceu. Quis mandar chamá-lo, porém é melhor que eu leia um pouco e durma". 86 A fadiga refletia-se então na qualidade dos encontros, constantemente medida e avaliada pelo atento pupilo como sendo puro desinteresse ou má vontade por parte do seu tutor: "Tudo bem. Na cama para ouvir Seibold. Acabou o livro (...) Foi-se sempre com desejo de se retirar e vou dormir". ${ }^{87}$ A impaciência de Seybold

\footnotetext{
${ }^{79}$ Ibidem, p. 1.229, grifos nossos.

${ }^{80}$ Ibidem, p. 1.234, grifos nossos.

${ }^{81}$ Ibidem, p. 1.260, grifos nossos.

82 Ibidem, p. 1.054.

83 Ibidem, p. 1.140.

${ }^{84}$ Ibidem, p. 1.260.

85 Ibidem, p. 1.261.

86 Ibidem, p. 1.205.

${ }^{87}$ Ibidem, p. 1.228.
} 
novamente é percebida e devidamente anotada pelo monarca: "Já estou na cama preparado para dormir depois da leitura do Seibold. 11h. Era curioso ver como Seibold queria apressar o fim da leitura". ${ }^{88} \mathrm{O}$ tom de desabafo que marca o diário do dia 1 de setembro de 1891 indica a insatisfação e sentimento de impotência de d. Pedro ante os problemas de saúde. Desde as 3 da madrugada, discorre sobre astronomia, buscando explicações para a falta de claridade natural que o impede de ler por conta própria: "Não sei que astronomia me servirá até poder ler sem vela. Por isso sempre quisera deitar-me mais tarde, se houvesse pessoas que me lessem". ${ }^{89}$ Continua suas divagações, limando os companheiros de exílio e comentando os motivos pelos quais não podem ajudá-lo com as leituras: "Seibold cansa e parece gostar de sair à noite. Aljezur é falta de vista. Mota Maia tem a família. Eu tenho estado doente. Já li muito na minha [vida] e o pé priva-me de sair do hotel".90 Barman ${ }^{91}$ comenta o pesado ônus que foi para um pequeno séquito cuidar e manter satisfeito d. Pedro II, ressaltando especialmente a participação de Seybold nesse processo. De fato, considerando o comprometimento do monarca para com os estudos, a curiosidade voraz que não se aplacava e o desejo de aprender cultivados durante toda a vida, acreditamos que o fardo maior tenha recaído sobre o tutor. No entanto, os atritos desencadeados pelo convívio diário, aparentemente velados, não impediram a continuidade do programa de estudos. Segundo Besouchet, com Seybold d. Pedro II "continuou a estudar árabe e sânscrito; seus cadernos de estudos hebraicos eram também numerosos" durante os anos de exílio. A autora relata ainda que a "sua letra tornara-se extremamente trêmula, quase ininteligível, nesse período".92

Em novembro de 1891, d. Pedro II começou a sentir os primeiros sintomas do que viria a ser uma pneumonia em poucos dias. Em 26 de novembro, o antigo monarca foi examinado pelo dr. Bouchart e, em seguida, pelo dr. Charcot. ${ }^{93}$ No mesmo dia, Pedro II faz as últimas anotações de próprio punho em seu diário. O prognóstico dos médicos não era dos melhores. A medicina de fins de século XIX não oferecia nenhum tratamento eficaz contra a pneumonia. No decurso da doença, agravada pelo diabetes, o pouco que os médicos de d. Pedro poderiam fazer era acompanhar o progresso

\footnotetext{
${ }^{88}$ Ibidem, p. 1.230.

${ }^{89}$ Ibidem, p. 1.230 .

${ }^{90}$ Ibidem, p. 1.230.

${ }^{91}$ BARMAN, Roderick J., op. cit., 2010, p. 550.

92 BESOUCHET, Lídia, op. cit., 1993, p. 570.

${ }^{93}$ BARMAN, Roderick J., op. cit., 2010, p. 557.
} 
da enfermidade e tentar aliviar ao máximo os seus efeitos. Passados pouco mais de 30 minutos após a meia-noite de 5 de dezembro falecia em Paris o segundo e último imperador do Brasil. Nos dias anteriores, porém, d. Pedro resistira, "mantendo seu interesse pelo mundo externo e sendo capaz de ditar comentários para que outros os registrassem em seu diário".94 José Murilo de Carvalho lança um palpite que parece fazer todo sentido dado o contexto dos últimos anos. Para o pesquisador, "talvez Seybold, em português afrancesado", 95 tenha assumido o controle do diário do monarca. Pudera! A ninguém melhor que ele, a nosso ver, poderia ter sido confiado realizar esta tarefa. Como um fiel escudeiro, Seybold participou dos momentos mais cruciais dos últimos anos de vida do ex-imperador, permanecendo ao seu lado no exílio e acompanhando de perto a doença que arrebatou a vida de seu aluno. As homenagens póstumas, seja no epitáfio preparado para a lápide de d. Pedro, seja na dedicatória de algumas publicações, sugerem que a relação entre ambos foi muito além do convívio restrito a professor e aluno. Além do mais, teria ele realizado um dos últimos desejos do monarca deposto: "não pediu o imperador, em seus últimos momentos, que o professor Seybold lesse a tradução do sânscrito de um texto sagrado?"96

\section{Considerações finais}

Pouco se sabe sobre quem teria sido Christian Friedrich Seybold. O orientalista alemão, com uma carreira acadêmica consolidada em Tübingen e marcada por muitas publicações, esteve no Brasil do Segundo Império para atuar como mestre orientalista do monarca Pedro II e o acompanhou durante o exílio que se seguiu com o fim do império no país. Por este motivo, é possível encontrar nas principais obras que versam sobre a vida de d. Pedro II algumas referências ao seu último professor de línguas orientais. Os dados biográficos sobre Seybold, no entanto, são fragmentários e insuficientes. Nossa inquietação, como já afirmado, nasceu justamente do descompasso que há entre as fontes pesquisadas: as biografias do monarca e o diário pessoal de d. Pedro. A primeira, marcada pela carência de elementos biográficos

\footnotetext{
${ }^{94}$ Ibidem, p. 557.

${ }^{95}$ CARVALHO, José Murilo de, op. cit., 2007, p. 242.

${ }^{9}$ ¿No pidió el emperador, en sus últimos momentos, que el profesor Seybold le leyese la traducción del sánscrito de un texto sagrado? BESOUCHET, Lídia. Renan y el emperador Pedro II. La “cuestión religiosa" en el Brasil. Revista de Cultura Brasileira, n. 50. Madri: Artes gráficas Benzal, 1979, p. 22, tradução nossa.
} 
sobre o último tutor do monarca. A segunda fonte, contrariamente, com inúmeras notas envolvendo o nome do professor, revelando assim que a participação do orientalista na vida de Pedro II foi intensa, o que impulsionou a nossa investigação. O encontro com o texto de Richard Hartmann (1922), entre outros, possibilitou a concretização do presente trabalho, descortinando alguns aspectos da vida de Seybold até então desconhecidos.

Dessa forma, foi possível avaliar as informações prestadas pelo alemão e confrontá-las com as demais fontes pesquisadas. Para citar um exemplo, encontramos em Hartmann ${ }^{97}$ a indicação de que Seybold teria se lançado no estudo das línguas americanas por sugestão de d. Pedro II. O testemunho disso está na edição de três obras antigas sobre a língua guarani, devidamente mencionadas anteriormente. O biógrafo Pedro Calmon, por sua vez, defende a participação de d. Pedro II no processo de edição do material em questão. Para ele, esses trabalhos foram realizados "de mão comum com o imperador". ${ }^{98}$ De fato, o diário de d. Pedro II mostra que o monarca estava acompanhando de perto a produção das obras. De acordo com suas anotações, entre o trabalho de tradução e as leituras que costumeiramente fazia durante as suas aulas com o professor Seybold, d. Pedro II examinava também as provas impressas do volume. Acompanhou a edição do material de janeiro a outubro de 1890, época em que um dos livros foi publicado. Registrava ele no dia 23 de janeiro de 1890: “(...) ainda continuei [a ler] a edição da arte do Guarani de Paulo Restivo que está publicando com o Seibold".99 Em 25 de setembro de 1890, Pedro II julgava positivamente o paratexto do livro: "Prefácio muito bem escrito por ele [Seybold] à edição do manuscrito sobre a língua guarani de Restivo que está publicando". ${ }^{100}$ No dia seguinte, 26 de setembro, a anotação revela que o monarca costumava opinar sobre a edição, porém não há como comprovar que as contribuições tenham sido acatadas: “(...) acabei de ler a dedicatória em latim e que há de acompanhar a edição da Arte da língua guarani de Restivo. Fiz-lhe apenas algumas reflexões". ${ }^{101}$ Em 14 de outubro, Pedro II parece não medir esforços para divulgar o livro: "vou dar a Nioac Brevis linguae Guarani gramatica hispaniae etc. editada pelo Seibold para que se escreva sobre ela no Gaulois". ${ }^{102}$ Finalmente,

\footnotetext{
${ }_{97}$ HARTMANN, Richard, op. cit., 1922.

${ }^{98}$ CALMON, Pedro, op. cit., 1975, p. 475.

99 ALCÂNTARA, Pedro de, op. cit., 1999, p. 846.

${ }^{100}$ Ibidem, p. 1.009.

${ }^{101}$ Ibidem.

${ }^{102}$ Ibidem, p. 1.019.
} 
em 17 de outubro, a obra estava sendo lançada no Congresso de Americanistas, em Paris: "Seibold apresentou exemplares de sua edição de gramática Guarani de Restivo".103 Os três níveis de informação, complementares, permitem vislumbrar não só os elementos constitutivos da carreira acadêmica de Seybold. Da mesma forma, oportunizam reconstruir, de maneira indireta, um dos aspectos do perfil de d. Pedro II enquanto tradutor de línguas orientais, que considerava ter a língua guarani ascendência asiática. ${ }^{104}$

Ao propor trazer novos dados sobre a vida de Christian Friedrich Seybold neste trabalho, pretendemos antes de tudo estimular futuras pesquisas, mostrando que há muitas lacunas a serem preenchidas e que possivelmente trarão contribuições importantes no âmbito da historiografia brasileira. Vale ressaltar que temos a consciência de que o objeto de pesquisa das biografias consultadas foi o último imperador do Brasil e, por extensão, o contexto político no qual estava imerso e desempenhava papel central. Se as pesquisas sobre o intelectual d. Pedro ainda são incipientes, parece mais que justificável que os mestres e colaboradores das diversas áreas de interesse de estudo do monarca tenham permanecido, de certa maneira, no ostracismo. Dessa forma, ao deslocar o foco do personagem principal para uma figura coadjuvante, objetivou-se apenas complementar informações, retificar possíveis equívocos e promover discussões acerca da participação desses agentes, especialmente Christian Seybold, na constituição do perfil intelectual do cidadão Pedro d'Alcântara.

\section{Referências bibliográficas}

ALCÂNTARA, Pedro de. Diário do imperador d. Pedro II. Organização: Begonha Bediaga. Petrópolis: Museu Imperial, 1999.

BARMAN, Roderick J. O imperador cidadão e a construção do Brasil. São Paulo: Unesp, 2010.

BEHN, Wolfgang. Concise biographical companion to index islamicus: an international who's who in Islamic studies from its beginnings down to the twentieth century. Bio-bibliographical supplement to index islamicus, 1665-1980, vol. III (N-Z). Leiden: Brill, 2004.

BESOUCHET, Lídia. Renan y el emperador Pedro II. La "cuestión religiosa" en el Brasil. Revista de Cultura Brasileira, n. 50. Madri: Artes gráficas Benzal, 1979, p. 3-22. Pedro II e o século XIX. $2^{\text {a }}$ edição revisada e ampliada. Rio de Janeiro: Nova Fronteira, 1993.

\footnotetext{
${ }^{103}$ Ibidem.

${ }^{104}$ Ibidem, p. 933.
} 
rev. hist. (São Paulo), n. 173, p. 303-327, jul.-dez., 2015 http://dx.doi.org/10.11606/issn.2316-9141.rh.2015.106223
Adriano Mafra \& Christiane Stallaert

Um orientalista alemão no Brasil Imperial. Christian Friedrich Seybold, o tutor de d. Pedro II

CALMON, Pedro. História de dom Pedro II. Rio de Janeiro: José Olympio; Brasília: INL, 1975.

CARVAlHO, José Murilo. D. Pedro II: ser ou não ser. Coordenação de Elio Gaspari e Lilia M. Schwarcz. São Paulo: Companhia das Letras, 2007.

DIBE, Fück. Index Islamicus. Islam, n. 12, 1922, p. 202-206.

ESS, Josef van. Christian Friedrich Seybold, professor für Orientalistik. 1859-1921. Lebensbilder aus Schwaben u. Franken, 14. Stuttgart, 1980, p. 416-432.

JAROUCHE, Mamede Mustafá. O desafio do tempo na tradução das Mil e uma noites. CICLO: DESAFIOS DA TRADUÇÃO LITERÁRIA. ABL, 2011, p. 73-88. Disponível em: < http://www.academia.org.br/abl/media/Revista\%20Brasileira\%2069\%20 \%20CICLOS.pdf>. Acesso em: 10 maio 2014.

KAY, Charles de. The arabian nights. The story of Sul and Schumul, oddly in a Christian setting. The New York Times, 8 agosto 1903, p. BR5. (Seção The New York Times Saturday Review of Books and Art).

LE BLANC, Claudine. Une Antiquité nouvelle. In: CHEVREL, Yves; D'HULST, Lieven; LOMBEZ, Christine (ed.). Histoire des traductions en langue française. Lagrasse: Verdier, 2012, p. 189-254.

L'ENCICLOPEDIA ITALIANA. Christian Friedrich Seybold. Disponível em < http://www. treccani.it/enciclopedia/ricerca/seybold/>. Acesso em: 06 abr. 2014.

HABA, Juan Piqueras. Cartografía islâmica de Sharq Al-Andalus. Siglos X-XII. Al-Idrīsī y los precursores. Cua. de Geogr. n. 86. Valência, 2009, p. 137-164. Disponível em: <http://roderic.uv.es/bitstream/handle/10550/31376/137-163. pdf?sequence=1>. Acesso em: 10 maio 2012.

HARTMANN, Richard. Kleine Mitteilungen und Anzeigen. Christian Friedrich Seybold. Der Islam. Journal of the History and Culture of the Middle East, v. 12, n. 3-4. Berlim: De Gruyter, 1922, p. 202-206.

HOUTSMA, Martijn Theodoor et al. First Encyclopaedia of Islam, 1913-1936. Leiden: Brill, 1936.

LYRA, Heitor. História de dom Pedro II: Fastígio: 1870-1880. Belo Horizonte: Itatiaia, 1977a. História de dom Pedro II: Declínio: 1880-1891. Belo Horizonte: Itatiaia, 1977b.

MAFRA, Adriano. O processo criativo de d. Pedro II na tradução do Hitopadeça. 449 f. Tese de doutorado em Estudos da Tradução, Programa de Pós-Graduação em Estudos da Tradução, Universidade Federal de Santa Catarina, Universiteit Antwerpen, Florianópolis, Antuérpia, 2015.

NALLINO, Carlo Alfonso. Necrologie: Christian Friedrich Seybold. Revista Degli Studi Orientali, n. 9, 1921-1923, p. 234-5.

SCHWARCZ, Lilia Moritz. As barbas do imperador: D. Pedro II, um monarca nos trópicos. São Paulo: Companhia das Letras, 1998.

SEYBOLD, Christian Friedrich. Fleischers Briefe an Hassler aus den Jahren 1823 bis 1870. Tübingen: J. C. B. Mohr (Paul Siebeck), 1914.

.Historia patriarcharum Alexandrinorum. Beryti: E. Typographeo Catholico, 1904. . Die Drusenschrift: Kitāb Alnoqat Waldawāir "Das Buch der Punkte und Kreise". Leipzig: M. Spirgatis, 1902. 
La España musulmana. Notas geográficas. Boletín de la Real Academia de la Historia, tomo 40. Madri, 1902, p. 553-4.

Geschichte von Sul und Schumul: Unbekannte Erzählung aus Tausend und einer Nacht. Leipzig: M. Spirgatis, 1902.

. Glossarium latino-arabicum ex unico qui exstat codice Leidensi undecimo saeculo in Hispania conscripto. Berlim: E. Felber, 1900.

Die arabische Sprache in den romanischen Ländern. In: GRÖBER, Gustave. Grundriß der romanischen Philologie. Strassburg: Karl J. Trübner, 1897.

Relaciones sobre Pedro Teixeira 1610. In: KUHN, Ernst Wilhelm Adalbert. Festgruss an Rudolf von Roth zum Doktor-Jubiläum. Stuttgart: G. Kohlhammer, 1893, p. 31-4.

. Lexicon Hispano-Guaranicum ("Vocabulario de la lengua Guarani"). Stuttgart:

G. Kohlhammer, 1893. Arte de la lengua Guaraní. Stuttgart: G. Kohlhammer, 1892.

. Brevis Linguae Guaraní Grammatica Hispanice ("Breve noticia de la lengua Guarani"). Stuttgart: G. Kohlhammer, 1890. Ibn al-Anbārī's Asrâr al-'Arabiya. Leiden: Brill, 1886.

SOARES, Noêmia Guimarães; SOUZA, Rosane de; ROMANELLI, Sergio (org.). Dom Pedro II: um tradutor imperial. 1 ${ }^{\text {a }}$ edição. Tubarão: Copiart, 2013.

STALLAERT, Christiane $\mathcal{E}$ ROMANELLI, Sergio. Entrada do Brasil na República mundial das letras. Mediações transatlânticas e diplomacia cultural de Dom Pedro II na elaboração de uma identidade letrada nacional. Nuevo mundo mundos nuevos, Débats. Sep. 2015. Disponível em < https://nuevomundo.revues. org/68197> Acesso em: 25 out. 2015.

VIERHAUS, Rudolf.Deutsche BiographischeEnzyklopädie. München:Walter de Gruyter, 2008.

WERKMEISTER, Walter. The near and middle East collection of the University Library of Tübingen. Bulletin (British Society for Middle Eastern Studies), vol. 9, n. 1, 1982, p. 82-7. 
